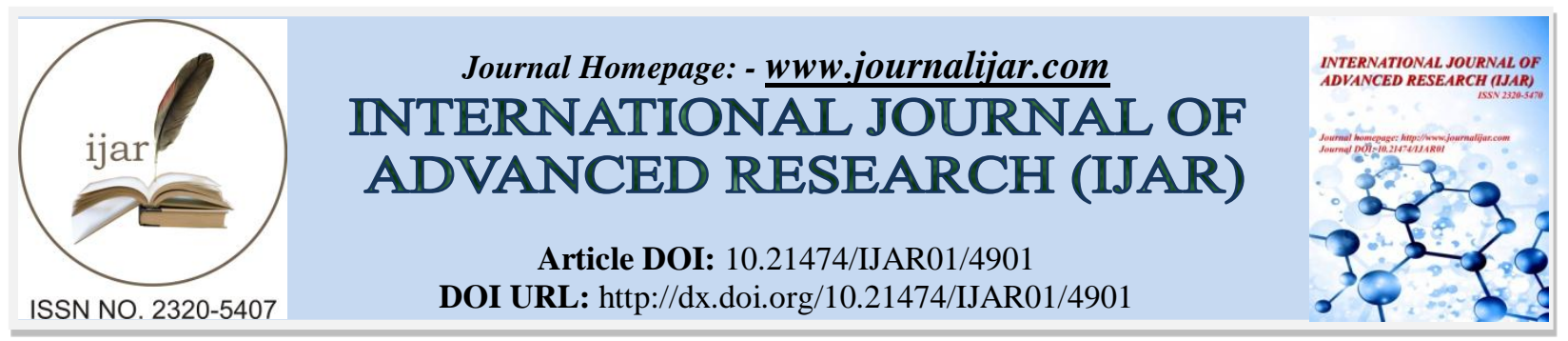

RESEARCH ARTICLE

\title{
EFFECTS OF NOVEL ANTIOXIDANTS COMPOSITE ON OXIDATIVE STABILITY OFREFINED, BLEACHED, AND DEODORIZED PALM OLEIN DURING REPEATED DEEP FRYING OF POTATO CHIPS AND SENSORY QUALITY OF FINAL FRIED FOOD.
}

Montaser. A. Mohamed, Shahat. A. Saber, AlShaimaa. S. Assem and Salma. F. Gomaa. Research and development department, Global innovation Center, Savola Foods Company, Cairo, Egypt.

\section{Manuscript Info}

Manuscript History

Received: 20 May 2017

Final Accepted: 22 June 2017

Published: July 2017

Key words:-

Deep frying-Antioxidant-sensory attributes-Oxidative stability

\section{Abstract}

In this study, the effect of a novel antioxidants composite has been evaluated during deep frying and the shelf life of fried food. The composite is a synergetic blend of synthetic and vitamin-based antioxidants, with effective chelators to obtain the highest oxidative stability impact during deep frying. The frying processes were carried at $180{ }^{\circ} \mathrm{C}$ for sliced potato chips. Sensory evaluation of the fried potato has been conducted under accelerated storage conditions to determine the effect of oil oxidative stability on the shelf life of fried food. The oxidative degradation of the oil was evaluated by measuring the induction period. Also, the fried oil samples were analyzed for their respective peroxide value, free fatty acid \%, content of conjugated dienes, P-anisidine value, induction period (IP) and color. The (\%) of oil absorption in the potato chips was also measured. Results showed that the composite has better stability against thermal oxidation when compared to TBHQ after multiple frying ( $\mathrm{P} \leq 0.05)$. Furthermore, sensory evaluation of the fried potatoes indicated that improving the frying oil oxidative stability has a positive impact on the sensory acceptance of final product. Consequently, the proposed composite is a synergetic ingredient that can improve the frying oil stability, and prolong final product self-life.

Copy Right, IJAR, 2017,. All rights reserved.

Shelf life is a main criteria while developing, producing, and marketing any food products. There is a high consumer demand for a products that maintain a fresh appearance, odor, and flavor for as long as possible. Furthermore, increasing the shelf life of product can reduce the costs for both producer and consumer. Fried food products are highly susceptible for losing freshness during shelf life. This is attributed to the high lipid content which make it more susceptible for lipid oxidation. In this regard, the quality and oxidative stability of the frying medium can alter the acceptance of the fried product[1] [2][3] Generally speaking, the lipid deterioration of frying oils is highly dependent on the chemical composition of oil. Vegetable oils that are of high content of poly-unsaturation, are more subjected to oxidative deterioration, compared to that of high content of oleic and saturated fatty acids, such as palm olein. The oxidative deterioration of frying oils, that are absorbed by food, can alter the functionality, sensory nutritive value of fried food. It can even alter the safety of food. [1] [4][5][6][7][8]. The oxidative products resulting from lipid oxidation, especially reactive oxygen species are associated with cell damage, resulting it severe complications including cardiovascular diseases and cancer. In a number of cross sectional studies, fried foods have been correlated to various cardiovascular risk factors[6]. Furthermore, the sensory attributed is one of the important

Address:- R\&D department, Global innovation Center, Savola Foods Company, Cairo, Egypt. 
quality factors of fried food that are highly sensitive to the quality and suitability of the frying oil. The degradation products formed in the frying oil interfere with the taste and flavor of fried food results in off-flavor. Consequently, these changes reduce consumer acceptance to the final product. In this regard, wide range of antioxidants, either synthetic or natural, are added to fats, oils, and foods containing fats to inhibit the development of off-flavors arising from the oxidation of unsaturated fatty acids [2][9][10][11] [12][13][14][5].

In this study, a novel antioxidants composite has been evaluated during deep frying of fresh potato chips. The composite is a synergetic blend of synthetic and vitamin-based antioxidants, with effective chelators, with the optimum ratios, to obtain the highest oxidative stability during frying. Refined, bleached, and deodorized (RBD) palm olein was used in this study because of its major commercial role in deep-fat frying. The primary objective of this study was to assess the frying performance of RBD palm olein treated with the prepared composite in comparison with the most commonly used antioxidant, TBHQ. A secondary objective was to study the oxidative stability and organoleptic quality of the fried potato chips produced in these systems under accelerated storage conditions for 30 days. The intent of the study was to determine the effect of oil oxidative stability on the shelf life of fried food, reflected through its organoleptic quality.

\section{Materials and Methods:-}

Materials. RBD palm olein (IV56) (Wilmar International Ltd.), TBHQ (DuPont), Ascorbyl palmitate (DuPont), Citric acid (DuPont), Dimethicone/E900 (Wacker Silicones). All chemicals and solvents used were of analytical grade. Fresh potatoes were peeled and sliced using a mechanical slicer. They were kept submerged in water at room temperature. They were then slightly dried out with tissue paper before weighing into $600 \mathrm{~g}$ batch for frying.

Sample preparation. Composite antioxidant was prepared by dissolving citric acid (50 ppm), ascorbyl palmitate (50 ppm), TBHQ (200 ppm), Dimethicone/E900 (7 ppm) in monopropylene glycol. The composite were allowed to stir until obtaining a homogenous mixture. Frying experiments were carried out in two systems that contained: RBD palm olein with novel antioxidant (System I); and RBD palm olein with TBHQ (System II). The temperature of RBD palm olien was brought up to $60^{\circ} \mathrm{C}$, then antioxidants were added to each system, respectively. The dose for both systems were 650 and 200 ppm for systems I and II, respectively.

Deep fat frying (DFF) experiments. Frying experiments were conducted in two replicates on each system. Samples was subjected to deep frying under the same conditions. A deep fat fryer with capacity 18 liters was used in the experiment. The fryer was filled with frying oil and the temperature was set at $180{ }^{\circ} \mathrm{C}$ throughout the trail. Oil samples was not replenished at any time during the experiment to achieve maximum deterioration possible. Each oil sample were used for the DFF of 8 successive batches of potato chips (600 gram each). At the end of frying, fryer was switched off and the temperature was allowed to drop to $60^{\circ} \mathrm{C}$. Oil samples for analysis were collected in amber bottles at $60^{\circ} \mathrm{C}$ for further analyses. Analysis of oil was carried out immediately after the frying experiment and completed within 4 weeks. All Chips samples were kept for sensory assessment.

Analysis of Oil: The official AOCS methods were employed for determinations of free fatty acid (FFA \%), and Peroxide value (PV), Anisidine value (AV), and conjugated diene (\%) [15]. The AV and conjugated dienes were measured using UV/Vis spectrophotometer Cary $60 \mathrm{UV}-\mathrm{Vis}$, Agilent Technology, Canada at 350 and $233 \mathrm{~nm}$, respectively. Oil color was measured in a 5.25 inch. cell in a Lovibond ${ }^{\circledR}$ Tintometer PFX8800, UK. The accelerated Oxidative Stability of Oils (OSI) was performed by determining the induction period (IP) of oil samples using a Metrohm Rancimat Model 679 (Metrohm Herisau, Switzerland). The experiment was carried out at $120^{\circ} \mathrm{C}$.

Oil and Moisture content in fried potato chips: The fat and moisture (\%) in potato chips was determined using a Near Infrared Transmission (NIT) analyzer (Infra-Lab, NDC, UK). Samples were first grinded for 60 seconds in a domestic food grinder to obtain small particles. The samples were then loaded into an elongated sample cell of $18 \mathrm{~mm}$ path length, packed and measured in the instrument. Samples were measured in duplicates.

Sensory analyses of fried potato chips. The sensory analysis was used to assess the organoleptic quality of the chips. The Fried potato chips were packed in laminated polythene bags and stored at $\left(40^{\circ} \mathrm{C}\right)$ for storage analysis. Samples were assigned codes to eliminate bias. During storage analysis, bags were sampled at 1-week intervals for a period of 4 weeks. Thirty panelists from the laboratory staff were selected to evaluate the sensory attributes of stored samples based on a five-point hedonic scale. Panelists were required to evaluate the overall acceptability of each sample using a numerical scale of 1 to 5 ( $1=$ not acceptable, $5=$ extremely good $)$. The panelist were also asked to 
state which sample they preferred the most if they could distinguish any difference (overall preference). This overall preference meant that they had to take into account any flavor of rancidity and undesirable taste [7][16] [17][18].

Statistical analysis. All data are presented as the mean + standard deviation (SD). Statistical analysis of all data was performed using 1-way ANOVA (StatView) whereas p values $<0.05$ were considered statistically Significant.

\section{Results and Discussion:-}

Changes in primary oxidation products: Evaluating the oxidative stability of frying oils includes measuring the primary and secondary breakdown products [12]. FFA content is a measure of the acidic components in the oil, which contributes to the development of off-flavors and off-odors in the fried product [12][15] At the end of the frying period, FFA contents were $0.0842 \%$ and 0.1155 for System I (composite-containing oil), and System II (TBHQ containing system), respectively. Composite system showed better FFA\%, however the difference was not significant $(\mathrm{P}>0.05)$. On the other hand, there was a significant improvement $(\mathrm{P}<0.05)$ between both systems in terms of peroxide value (see table 1 ).

Changes in secondary oxidation products: The PV test is a good measurement for oxidative deterioration in frying oils. However, very rancid oils can have a reduced PV value, while having high values of anisidine (AV). Consequently, the anisidine value (AV) and Totox value are used to show the overall oxidation state [12][19]. As it is shown in table 1, there is a significant improvement in AV values obtained in case of composite system, compared to TBHQ system. This indicates that the composite has a positive impact on both primary and secondary oxidative products. This was reflected in terms of total Totox number, calculated as AV $+2 \mathrm{PV}$. The lower the Totox value, the better the quality of oil. Composite system showed a significant improvement in totox values (19.5, 9.9 for TBHQ sample and composite systems, respectively).

Oxidation of polyunsaturated fatty acids (PUFA) leads to the formation of primary and secondary oxidation products. Such products are formed due to the isomerization of double bonds, forming products that contain trans double bounds and conjugated bond systems. Compounds and amounts of these products vary, depending on the oxidative conditions. To evaluate the oxidation state of oil, method determines the diene conjugation of unsaturated linkage present, expressing the value as a percentage of conjugated dienoic acid[1][20]. The results of conjugated diene $\%$ showed that the composite has less $\%$ of conjugated double bond compounds. However, the difference is not significant $(\mathrm{P}<0.05)$.

Changes in Color, and Rancimat test: The color of frying oil darkens during frying, as a result of oxidation and formation of browning pigments from the potato chips [21]. At the end of the frying period, the red (R) and yellow (Y) color units were measured for TBHQ and composite Systems. The results showed that the difference in color was not significant $(\mathrm{P}>0.05)$. Augustin et al. stated that darkening of palm olein could not be exclusively linked to the oxidative deterioration of oil. Therefore, it is not accurate to evaluate frying oil quality by only monitoring the changes in color during frying [20].

A commonly used method for evaluating the oxidative stability of oil is the measurement of induction period (IP). IP reflects the time during which the oil can resist oxidation, due to the presence of naturally occurring antioxidants or added antioxidant. The IP was measured using rancimat test [2] [12] [19][22]. As it is clear in table, System I, containing the synergetic composite, showed significantly better induction period, reflecting the extended oxidative stability and shelf life of the composite containing frying oil.

Table 1:- Physio-chemical characterizes of frying oils during DFF.

\begin{tabular}{|l|l|l|l|l|l|l|}
\hline & \multicolumn{2}{|c|}{ Initial value } & \multicolumn{2}{c|}{ Final value } & \multicolumn{2}{c|}{ Difference } \\
\hline & FFA $(\%)$ & CDs $(\%)$ & FFA & CDs & FFA $(\%)$ & CDs $(\%)$ \\
\hline System I & $0.04 \pm 0.0$ & - & $0.124 \pm 0.093$ & 0.18565 & 0.084 & 0.18565 \\
\hline System II & $0.038 \pm 0.0$ & - & $0.153 \pm 0.052$ & 0.1945 & 0.115 & 0.1945 \\
\hline & Color (Red) & IP(h) & Color (Red) & IP (h) & Color(Red) & IP(h) \\
\hline System I & $2.9 \pm 0.0$ & $9.50 \pm 1.5$ & $6.4 \pm 0.1$ & $18.49 \pm 0.5$ & 3.4 & 8.99 \\
\hline System II & $3 \pm 0.1$ & $10.25 \pm 1$ & $6.5 \pm 0.2$ & $14.39 \pm 1.1$ & 3.6 & 4.24 \\
\hline
\end{tabular}

\begin{tabular}{|c|c|c|c|}
\hline & Initial Value & Final Value & Difference \\
\hline
\end{tabular}




\begin{tabular}{|l|l|l|l|l|l|l|l|l|l|}
\hline & P-AV & PV & Totox \# & P-AV & PV & Totox \# & P-AV & PV & Totox \# \\
\hline System I & 2.08 & 0.42 & 2.881 & 8.31 & 2.24 & 12.79 & 6.2315 & 1.842 & 9.9167 \\
& \pm 0.94 & \pm 0.05 & & \pm 1.04 & \pm 0.45 & & & & \\
\hline System II & 1.58 & 0.55 & 2.684 & 11.67 & 5.298 & 22.26 & 10.089 & 4.748 & 19.585 \\
& \pm 0.65 & \pm 0.15 & & \pm 1.25 & \pm 0.67 & & & & \\
\hline
\end{tabular}

Each value in the table represents the mean \pm standard deviation of three analyses from two replications. $*$ reflects significantly $(P<0.05)$ different between the mean values.

Oil and Moisture content in fried potato chips: Frying oil tends to be absorbed into the food during frying process. Oil absorption in fried food may be as high as $40-50 \%$ of the food weight, making them calorie dense and may contribute to obesity [6][23]. Oil content is a very important parameter in potato chips. On option of making traditional potato chips healthier is by reducing the oil content in the chips. Number of research have been dealing with reducing oil absorption in frying food using certain additives [24] [25]. A Japanese patent showed a method to reduce oil absorption in fried food by mixing at least one kind of oil with chemically-modified starch[26]. The fried food portion produced by this method showed to have lower oil content and acceptable taste, texture and appearance. In another study, Methylcellulose (MC) and hydroxypropyl-methylcellulose (HPMC) were used for coating chips and dough discs to reduce oil uptake in deep-fat frying [27]. However, few research have related the use of antioxidant to limit the oil absorption in fried food. In a US patent, an additive comprising a bio phenol-based extract was incorporated into a frying oil composition for reducing oil adsorption into food fried. The bio-additive developed was formulated from various parts of Rutaceae plant family. It proved to function as a natural fat antioxidant, oil absorption inhibitor with other health promoting properties making the fried food less hazardous to health[26].

The oil and moisture (\%) are represented in table 2. Rotato chips fried with composite system (System I) has significantly lower fat $(\mathrm{p}<0.05)$ content compared to that fried with TBHQ system (System II). This is considered an added value from both a consumer and market prospective. Lower oil content is desirable for nutritional reasons. Furthermore, it is favorable for the growing market trend toward healthier food snacks.

Sensory evaluation of fried potato chips: Sensory evaluation was employed to assess the effect of an antioxidant on the organoleptic quality of fried potato chips. Although somewhat subjective, sensory evaluation remains the ultimate measure of rancidity, as no combination of chemical or physical tests is currently capable of assessing the composite sensory attributes of a food. [14][7][5] The sensory perception of the sensory panel members, in terms of overall acceptability and overall preference $(\%)$, to word the potato chips during accelerated storage is represented in table 3.

The results showed that potato chips of the composite system has significantly $(p>0.05)$ higher overall acceptability, compared to that of TBHQ system during the storage period. Also it was clear that acceptability to the fried chips decreased regularly with increasing time of storage for both systems (see table 3 ). When panelists were asked to discriminate between the two systems for overall preference, they showed a preference for potato chips fried with the system 1 (composite system). This was very pronounced from week 1 after storage and continued until the last day of storage (Table 3).

When sensory analysis data were compared with chemical measurements of oxidation, it was clear that the results of sensory preference for potato chips over time agreed with changes in PV, AV and rancimat test values for the oil systems. In other words, the panel did detect the presence of rancid notes. Consequently, it can be concluded that the flavor likability of fried food is affected by performance and oxidative stability of frying oil. The presence of rancidity notes and correlation between oxidation parameters values and sensory panel data have been observed in other studies Kalra et al concluded that the frying medium plays an important role in the shelf life of a fried product. In another study done by Jaswir et al, it was proved that lowering the rate of oxidation of oil during deep-fat frying, by adding natural antioxidant, contributed to measured sensory acceptability of fried potato chips (16).

Table 2:- Oil absorption and moisture \% of fried potato chips.

\begin{tabular}{|c|c|c|}
\hline & Moisture \% & Oil absorption \% \\
\hline System I & $1.355 \pm 0.08$ & $35.91 \pm 0.15^{*}$ \\
\hline System II & $1.31 \pm 0.15$ & $37.15 \pm 0.01^{*}$ \\
\hline
\end{tabular}

* refers to significantly $(P<0.05)$ different between the mean values. 
Table 3:- Sensory Scores for over all acceptance of Fried Potato Chips Stored under accelerated storage conditions.

\begin{tabular}{|c|c|c|c|c|}
\hline & \multicolumn{2}{|c|}{ Over all Acceptability (1 to 5) } & \multicolumn{2}{c|}{ Over all preference (\% of panelists) } \\
\hline & System I & System II & System 1 & System II \\
\hline Week 1 & $4^{\mathrm{b}}$ & $2.9^{\mathrm{b}}$ & 71.8 & 20.5 \\
\hline week 2 & $3.19^{\mathrm{b}}$ & $2.5^{\mathrm{b}}$ & 78.6 & 18.4 \\
\hline week 3 & $2.8^{\mathrm{b}}$ & $1.3^{\mathrm{b}}$ & 83.3 & 16.6 \\
\hline week 4 & $2.1^{\mathrm{b}}$ & $1.1^{\mathrm{b}}$ & 93.4 & 6.6 \\
\hline
\end{tabular}

${ }^{a} 1=$ not acceptable, $5=$ extremely good. $)^{b}$ Mean of single determination of 30 observations. Means within each column with the different subscripts are significantly $(P<0.05)$ different. ${ }^{b}$ Numbers represent the percentage of panelists who expressed their preference for particular sample.

\section{Conclusion:-}

The results of this study have shown that the addition of the novel composite antioxidants to RBD palm olein improves its oxidative stability when used as a deep-fat frying oil. This can be attributed to the synergetic effect of the components of the composite that reduced the oxidative deterioration of oil during deep frying. The accelerated storage study of fried potato chips carried out at $40^{\circ} \mathrm{C}$ showed the synergetic composite had a positive impact on the organoleptic properties of fried chips. Thus, it can be concluded that the proposed composite can enhance oxidative stability for commercial application of frying oils.

\section{Acknowledgment:-}

The authors would like to acknowledge Americana group, Egypt for their contribution in performing frying test in their facilities and sensory analysis, depending on their trained staff.

\section{References:-}

1. E. M. Marinova, K. a. Seizova, I. R. Totseva, S. S. Panayotova, I. N. Marekov, and S. M. Momchilova, "Oxidative changes in some vegetable oils during heating at frying temperature," Bulg. Chem. Commun., vol. 44, no. 1, pp. 57-63, 2012.

2. E. Choe and D. B. Min, "Chemistry of deep-fat frying oils," J. Food Sci., vol. 72, no. 5, pp. 1-9, 2007.

3. B. Mobin Siddique, A. Ahmad, M. Hakimi Ibrahim, S. Hena, M. Rafatullah, and M. Omar A. K, "Physicochemical properties of blends of palm olein with other vegetable oils," Grasas y Aceites, vol. 61, no. 4, pp. 423429,2010 .

4. K. Warner and S. Knowlton, "Frying quality and oxidative stability of high-oleic corn oils," J. Am. Oil Chem. Soc., vol. 74, no. 10, pp. 1317-1322, 1997.

5. Y. B. Che Man and C. P. Tan, "Effects of natural and synthetic antioxidants on changes in refined, bleached, and deodorized palm olein during deep-fat frying of potato chips," J. Am. Oil Chem. Soc., vol. 76, no. 3, pp. 331-339, 1999.

6. P. Guallar-Castillón et al., "Consumption of fried foods and risk of coronary heart disease: Spanish cohort of the European Prospective Investigation into Cancer and Nutrition study.," BMJ, vol. 344, no. jan23_3, p. e363, 2012.

7. X.-Q. Xu, V. H. Tran, M. Palmer, K. White, and P. Salisbury, "Chemical and physical analyses and sensory evaluation of six deep-frying oils," J. Am. Oil Chem. Soc., vol. 76, no. 9, pp. 1091-1099, 1999.

8. J. A. Thompson, W. A. May, M. M. Paulose, R. J. Peterson, and S. S. Chang, "Chemical reactions involved in the deep-fat frying of foods. VII. Identification of volatile decomposition products of trilinolein1," J. Am. Oil Chem. Soc., vol. 55, no. 12, pp. 897-901, 1978.

9. M. Daniela, C. Cristina, M. Elina, N. Sammán, L. Aparecida, and G. Gonçalves, "Degradation in soybean oil , sun fl ower oil and partially hydrogenated fats after food frying, monitored by conventional and unconventional methods," Food Control, vol. 22, no. 12, pp. 1920-1927, 2011.

10. S. P. Koh and K. Long, "Oxidative stability study of virgin coconut oil during deep frying," J. Trop. Agric. Fd. Sc, vol. 40, no. 1, pp. 35-44, 2012.

11. E. C. J.Chung, J.Lee and E. Choe, "Oxidative Stability of Soybean and Sesame," vol. 69, no. 7, pp. 574-578, 2004.

12. G. M. Ruiz, M. V. R. Méndez, and J. Velasco, "Review Article Antioxidants in frying: Analysis and evaluation of ef fi cacy," Eur. J. Lipid Sci. Technol., pp. 1441-1450, 2014.

13. K. D. Petersen, G. Jahreis, and J. Fritsche, "Research Article Chemical and sensory assessment of deep - frying oil alternatives for the processing of French fries," Eur. J. Lipid Sci. Technol., vol. 115, pp. 935-945, 2013. 
14. D. M. Hack, P. L. B. Jr, S. W. H. Jr, D. M. Hack, P. L. B. Jr, and S. W. H. Jr, "Nutrition, Sensory Evaluation , and Performance Analysis of Trans fat-Free, Low Alpha-Linolenic Acid Frying Oils and Performance Analysis of Trans Fat-Free ," J. Foodserv. Bus. Res., vol. 12, no. 1, pp. 42-54, 2009.

15. T. N. Semb, "Analytical Methods for Determination of the Oxidative Status in Oils," Norwegain University of SCience and Technology, 2012.

16. M. I. Khan, M. R. Asha, K. K. Bhat, and S. Khatoon, "Studies on chemical and sensory parameters of coconut oil and its olein blends with sesame oil and palmolein during wheat flour-based product frying," J. Food Sci. Technol., vol. 48, no. 2, pp. 175-182, 2011.

17. E. Yilmaz, "Performance of Different Natural Antioxidant Compounds in Frying Oil," vol. 54, no. 1, pp. 21-30, 2016.

18. M. Gibis, M. Kruwinnus, and J. Weiss, "Impact of different pan-frying conditions on the formation of heterocyclic aromatic amines and sensory quality in fried bacon," FOOD Chem., vol. 168, pp. 383-389, 2015.

19. S. P. Koh, N. Arifin, C. P. Tan, M. S. A. Yusoff, K. Long, and O. M. Lai, "Deep Frying Performance of Enzymatically Synthesized Palm-Based Medium- and Long-Chain Triacylglycerols (MLCT) Oil Blends," Food Bioprocess Technol., vol. 4, no. 1, pp. 124-135, 2011.

20. K. Bordin, M. T. Kunitake, K. K. Aracava, and C. S. F. Trindade, "Changes in food caused by deep fat frying A review," Archivos Latinoamericanos de Nutricion, vol. 63, no. 1. pp. 5-13, 2013.

21. E. De Marco, M. Savarese, C. Parisini, I. Battimo, S. Falco, and R. Sacchi, "Frying performance of a sunflower/palm oil blend in comparison with pure palm oil," Eur. J. Lipid Sci. Technol., vol. 109, no. 3, pp. 237-246, 2007.

22. S. Lalas and V. Dourtoglou, "Use of rosemary extract in preventing oxidation during deep-fat frying of potato chips," J. Am. Oil Chem. Soc., vol. 80, no. 6, pp. 579-583, 2003.

23. F. Pedreschi and P. Moyano, "Oil uptake and texture development in fried potato slices," J. Food Eng., vol. 70, no. 4, pp. 557-563, 2005.

24. M. Mellema, "Mechanism and reduction of fat uptake in deep-fat fried foods," Trends Food Sci. Technol., vol. 14, no. 9, pp. 364-373, 2003.

25. I. S. Saguy and D. Dana, "Integrated approach to deep fat frying: Engineering, nutrition, health and consumer aspects," J. Food Eng., vol. 56, no. 2-3, pp. 143-152, 2003.

26. F. M. Suhaila Mohamed, "Cooking oil composition with additive to reduce oil absorption," US 8425969 B2, 2013.

27. M. A. García, C. Ferrero, N. Bértola, M. Martino, and N. Zaritzky, "Edible coatings from cellulose derivatives to reduce oil uptake in fried products," Innov. Food Sci. Emerg. Technol., vol. 3, no. 4, pp. 391-397, 2002. 